\title{
Evolution of the Water Resources System Based on Synergetic and Entropy Theory
}

\author{
Qilin Zhu*, Laixin Shen, Peibin Liu, Yuefen Zhao, Yi Yang, \\ Daying Huang, Ping Wang, Jinpeng Yang
}

Beijing Institute of Water, No. 21, Chegongzhuang West Road, Haidian District, Beijing 100048, China

Received: June 4, 2015

Accepted: August 27, 2015

\begin{abstract}
In the context of the double impacts of climate change and strong human intervention on the water resources system, showing the system's evolution process and predicting the future is necessary, which plays an important role in evaluating the implemented water resources management measures, proposing future measures, and promoting the sustainability of water resources. This paper explored to apply synergetic theory and entropy theory in the study of the evolution of water resources. Considering water resources as a dissipative system comprising a resource subsystem, social subsystem, economic subsystem, ecological subsystem, and environmental subsystem, this paper proposed a new method called system evolution entropy through optimization selection of order parameters and order degree calculation. Using Beijing as a case study, we quantitatively showed the evolution process of a water resources system from 2000 to 2013 and predicted the evolution direction in recent years. The results indicate that Beijing's water resources system oscillated slightly with a non-persistent direction in 2000-07, but evolved toward order continuously after the 2008 Summer Olympic Games. Good consistency between the changes of system evolution entropy and the actual changes of Beijing's water resources system, and socio-economic and ecological environments through comparative analysis demonstrated that the study results fit the actuality well, i.e. the changes of system evolution entropy reveal the evolution process well, thereby indicating that this method exhibits good feasibility, adaptability, and effectiveness. Additionally, Beijing's water resources system will continue evolving toward order over the next few years by the prediction according to this method.
\end{abstract}

Keywords: water environment, water resources system evolution, synergetic and entropy theory system evolution entropy, Beijing

\section{Introduction}

Water is an origin of life, an essential factor for production, and a basis for ecology. Water resources not only relate to flood safety, drinking water safety, and food security, but also to economic, ecological, and national security. The natural water resources system as a giant complicated system has its natural evolution processes

*e-mail: wxzq1@126.com within a range of temporal and spatial scales in the environments. However, because of global climate changes and the intense impact of human activities at present such as abnormally changing precipitation - the more water withdrawn from and wastewater discharged into rivers, the more evolution of natural water resources system is disturbed. What is more, water problems have happened frequently in some regions, especially in mega cities (like Beijing), such as serious water shortages, severe water pollution, and deterioration of the water eco- 
logical environment, which results in serious impact upon the water resources system. Moreover, in order to cope with water problems, water policies and integrated water resources management have been implemented, which inevitably influence the evolution of the water resources system. In this case, what is the mechanism of the evolution of the water resources system, and how does the water resources system evolve considering these combined influences? What are the effects of these implemented management policies and measures? These are difficult to know. Therefore, it is important to study the evolution of the water resources system clearly and predict its direction, which can greatly assist a region's integrated water resources management and their sustainable development.

Much literature has been dedicated to the study of the water resources system. Pandey et al. [1] discussed an indicator-based framework to assess adaptive capacity of the water resources system in the Nepalese river basins. Asefa et al. [2] evaluated water resources system performance under varying climatic conditions focused on reliability, resilience, and vulnerability. $\mathrm{Li}$ et al. [3] estimated resilience for water resources systems. Liu et al. [4] also evaluated water resources system resilience, but emphasized its social-ecological dynamic under the interactions of humans and nature, and presented a quantitative assessment method. Du et al. [5] and Wang et al. [6] proposed a set pair analysis method to measure the state of the water resources system. Ahmad et al. [7] presented a new approach, spatial system dynamics, to simulate the water resources system. Hui et al. [8] applied coordination theory of a complex system in the water resources system and constructed a coordination evaluation index system to analyze it. However, few authors dedicated to its study have revealed its evolution mechanisms and quantitatively shown the evolution process.

Entropy was originally a thermodynamic construct, but now it is one of the most important concepts of modern science. Entropy theory is now widely applied in natural and social science fields [9], including information theory, physics, biology, ecology, sociology, economics, etc. - and especially in system evolution, where it has good universality. Many applications have been found in this field, for example biological system evolution [10], ecosystem evolution [11-13], geographical system evolution [14], and so on. The fields of water resources and water-related fields include a considerable amount of literature on water utilization structure evolution [15-17], groundwater environment evolution [18], groundwater depression cones evolution [19], river water quality evolution [20, 21], and hydrologic cycle evolution [22-24]. Especially in groundwater flow system evolution, fruitful studies have achieved academic achievements in recent years. $\mathrm{Xu}$ and $\mathrm{Du}$ [9] and $\mathrm{Su}$ [25] applied information entropy to calculate the entropies of groundwater flow system from the system's dissipative structure characteristics, successfully demonstrated the evolution process in a certain number of years, and found that groundwater withdrawal is the main driving force of groundwater flow system entropy variation through a newly presented method of grey correlation analysis. These studies have made an important contribution to the advancement of groundwater flow system evolution using entropy theory.

Zhang et al. [26] demonstrated that groundwater flow systems in the quaternary of Hebei Plain have undergone three major evolution stages since the Last Glacial Maximum. Bense et al. [27] showed the evolution of shallow groundwater flow systems in areas of degrading permafrost in response to climate-warming scenarios. Belitz et al. [28] evaluated the character and evolution of the regional groundwater flow system in the central part of the western San Joaquin Valley, with particular emphasis on the deposits overlying the Corcoran Clay Member of the Tulane Formation. Jiang et al. [29] studied the evolution mechanism of groundwater systems based on the dissipative structure theory. Liu et al. [30] proposed a wavelet entropy method to measure hydrological sequence complexity and show the evolution of groundwater resource systems. However, so far the application of entropy in the evolution of the water resources system has almost not been publicly reported. Compared with the achievements of groundwater flow system evolution, this paper recognized the system's dissipative structure characteristics and applied entropy theory to study the evolution as well. However, we propose a new perspective to show the system's evolution mechanism and process, namely that the evolution of the water resources system is under the collaborative evolution of its subsystems (see the section Synergetic Theory and Water Resources System in detail). Additionally, we constructed system evolution entropy derived from information entropy to quantitatively show the evolution of the water resources system.

In thermodynamic terminology, the water resources system, as an open system, can be described as a dissipative system that flourishes by consuming exchange of matter, energy, and information with surrounding environments. This exchange has similar transmission characteristics with the thermodynamic system, and along with the exchange, the order/disorder of the water resources system is changing and thus the system is evolving from a dissipative structure to another dissipative structure. Generally, entropy stands for disorder or uncertainty, which can be interpreted as a measure of the amount of disorder (or chaos) within a system [31, 32]. In this case, it can be understood that the evolution process of the water resources system is the process of change of the system's entropy. As a consequence, the application of entropy theory to the study of its evolution has a good theoretical basis.

The aim of this paper is to introduce entropy theory into research of the evolution of the water resources system in Beijing, showing the evolution process over the years and predicting evolution direction in the future, which can support decision-making for integrated water resources management and make for its orderly evolution and sustainable development. On the basis of revealing the dissipative structures and collaborative evolution of the five subsystems of the water resources system, this paper constructs a 
system of evolution entropy derived from information entropy and synergetic theory to quantitatively show its evolution. As a case study in Beijing, this paper calculated system evolution entropy in 2000-13 and showed the evolution process. Through comparative analysis of the changes of system evolution entropy and the actual changes in Beijing's water resources system plus socio-economic and ecological environments, we found that the results of the entropy changes fit the actuality well, i.e., the changes of system evolution entropy reveal the evolution process well, thereby indicating that this method exhibits good feasibility and effectiveness.

\section{Materials and Methods}

\section{Study Area}

Beijing, the capital of China, is located in northern China with an area of about $16,410 \mathrm{~km}^{2}$, more than $60 \%$ of which is formed by hills and plateaus. The region lies in the temperate sub-humid continental monsoon climate zone with uneven spatial and temporal distributions of precipitation, and frequent dry years. Beijing has a mean annual precipitation of about $585 \mathrm{~mm}$ (1956-2000) and the precipitation of the flood season (June to September) accounts for $83.5 \%$ of annual precipitation. The corresponding total volume of water resources available is 3.74 billion $\mathrm{m}^{3}$. However, due to climate change, average annual precipitation was $506 \mathrm{~mm}$ in 2000-2013 - a reduction of $13.5 \%$ compared with the foregoing precipitation. As a result, total volume of water resources dropped by $36.6 \%$ down to a mere 23.7 billion $\mathrm{m}^{3}$.

As a mega city, Beijing has a large population of about 21.15 million inhabitants and a prosperous economy of about \$300 billion USD (Gross Domestic Product, GDP) in 2013. Compared with 2000, the population has increased by $55 \%$ and nominal GDP grew by nearly 5.2 times. GDP per capita increased from 24,000 yuan in 2000 to 93,000 in 2013, approaching an increase of four times. As a result of the sharply increasing population, rapid economic growth, and an improving standard of living, water consumption increased from 3.46 billion $\mathrm{m}^{3}$ in 2002 to 3.64 billion $\mathrm{m}^{3}$ in 2013. Domestic water consumption alone increased from 1.08 to 1.62 billion $\mathrm{m}^{3}$. Because of the limited surface water resources, groundwater supplies most of the water demand, whose proportion of total water supply achieved $77.6 \%$ in 2004 in particular, and then it declined slightly to $55.1 \%$ in 2013. Reclaimed water as a new source accounts for a greater proportion of water supply, with a percent increasing from 5.7 in 2003 to 22.1 in 2013, which is used for non-potable uses (e.g. replenishing river water, toilet flushing, road cleaning, and landscaping). At present, Beijing has suffered many water problems, such as serious water shortages, groundwater overexploitation, rivers drying up, severe water pollution, and deterioration of the water ecological environment - all of which have seriously impacted sustainable water resources development.

\section{Synergetic Theory and Water Resource Systems}

Synergetics is the theory of studying how the system evolves through the cooperation of subsystems. Synergetic theory considers that a system can be divided into several subsystems, and there are exchanges of matter, energy, and information among a system's elements, between elements and subsystems, among subsystems, and between the system and the environment. Moreover, these exchanges lead to competition and cooperation among the subsystems. Competition contributes to the imbalances in the development of each subsystem, whose result is greater imbalances and differences in the system, and promotes the evolution of the system. Cooperation represents coordination and collaboration of subsystems and dominates the overall evolution of the system. Cooperation leads to an orderly evolution of the system, and a lack of cooperation leads to disorder.

As mentioned above, a water resources system is a dissipative system exchanging matter, energy, and information with the environment. From the perspective of synergetic theory that considers the natural-artificial attributes of the water resources system, such a system can be thought of as comprising the five subsystems: namely the resource subsystem, social subsystem, economic subsystem, ecological subsystem, and environmental subsystem that interact and are inter-restricted. The resource subsystem reflects the stability and renewable capability of the water resources system, and the social subsystem reflects the safeguard capacity of adequate supplies of clean water and the equity of water use. The economic subsystem aims at priority of efficiency, reflecting the supporting role of economic activities and the efficient use of water resources. The ecological subsystem reflects the inherent ecological function of water resources under natural conditions. In addition, the environmental subsystem mainly reflects water quality on behalf of the water environment.

Due to limited water resources, the five subsystems have intense competition for water. This competition creates the greatest power for putting the water resources system away from equilibrium, creating conditions for selforganization evolution of the system. In addition, cooperation also exists among the five subsystems, the goal of which is to make the whole water resources system evolve toward a more orderly structure so that the water resources system is better able to adapt to external changes. From these attributes and evolutionary characteristics of the water resources system, it is obvious that we can apply the synergetic theory in the water resources system and use it to study the evolution of the water resources system.

Essential in synergetics is the concept of the order parameter, which is the parameter of description of the macroscopic order degree of the system. The order parameter not only governs the change of other parameters and the behavior of subsystems, but also dominates the evolution of the whole system. Therefore, whether the water resources system evolves toward order depends on the cooperation of the order parameters of the five subsystems. Good cooperation 
Table 1. The selected order parameters and their values in 2000-13.

\begin{tabular}{|c|c|c|c|c|c|c|c|c|c|c|c|c|c|c|c|c|}
\hline \multirow{2}{*}{ Subsystem } & \multirow{2}{*}{$\begin{array}{c}\text { Order } \\
\text { parameter }\end{array}$} & \multirow{2}{*}{ Unit } & \multicolumn{14}{|c|}{ Year } \\
\hline & & & 2000 & 2001 & 2002 & 2003 & 2004 & 2005 & 2006 & 2007 & 2008 & 2009 & 2010 & 2011 & 2012 & 2013 \\
\hline \multirow{2}{*}{$\begin{array}{l}\text { Resource } \\
\text { subsystem }\end{array}$} & UR & $\%$ & 239.6 & 202.8 & 215.0 & 183.4 & 151.9 & 137.9 & 138.9 & 125.2 & 83.0 & 120.9 & 112.1 & 98.1 & 64.7 & 100.1 \\
\hline & GL & $\mathrm{m}$ & -15.4 & -16.4 & -17.3 & -18.3 & -19.0 & -20.2 & -21.5 & -22.8 & -22.9 & -24.1 & -24.9 & -24.9 & -24.3 & -24.5 \\
\hline \multirow{2}{*}{$\begin{array}{l}\text { Social } \\
\text { subsystem }\end{array}$} & TPC & $10^{4} \mathrm{~m}^{3} / \mathrm{d}$ & 367.1 & 370.7 & 428.0 & 429.0 & 399.0 & 347.5 & 372.7 & 391.0 & 422.5 & 424.0 & 445.0 & 473.0 & 490.0 & 523.0 \\
\hline & SE & - & 0.9 & 0.7 & 1.7 & 1.4 & 2.5 & 2.0 & 1.6 & 1.0 & 1.0 & 1.1 & 1.0 & 1.8 & 1.8 & 1.7 \\
\hline \multirow{2}{*}{$\begin{array}{l}\text { Economic } \\
\text { subsystem }\end{array}$} & GDP-PC & $10^{4}$ yuan & 2.4 & 2.7 & 3.1 & 3.5 & 4.1 & 4.6 & 5.2 & 6.0 & 6.4 & 6.7 & 7.4 & 8.2 & 8.7 & 9.3 \\
\hline & WCP-GDP & $\mathrm{m}^{3} / 10^{4}$ yuan & 127.8 & 104.9 & 80.2 & 71.5 & 57.4 & 49.5 & 42.3 & 35.3 & 31.6 & 29.2 & 24.9 & 22.1 & 20.1 & 18.7 \\
\hline \multirow{2}{*}{$\begin{array}{l}\text { Ecological } \\
\text { subsystem }\end{array}$} & EWC & million $\mathrm{m}^{3}$ & 43.0 & 30.0 & 80.0 & 60.0 & 61.0 & 109.0 & 162.0 & 272.1 & 321.9 & 362.8 & 397.0 & 446.8 & 567.4 & 592.1 \\
\hline & DRR & $\%$ & 11.5 & 15.5 & 19.2 & 21.0 & 19.8 & 17.5 & 19.0 & 15.5 & 9.5 & 8.7 & 13.5 & 13.8 & 11.3 & 9.1 \\
\hline \multirow{2}{*}{$\begin{array}{l}\text { Environmental } \\
\text { subsystem }\end{array}$} & WTR & $\%$ & 39.4 & 42.0 & 45.0 & 50.1 & 53.9 & 62.4 & 73.8 & 76.2 & 78.9 & 80.3 & 81.0 & 81.7 & 83.0 & 84.6 \\
\hline & RQI & $\%$ & 56.5 & 58.5 & 55.5 & 66.0 & 60.0 & 54.0 & 58.7 & 49.3 & 52.0 & 46.1 & 47.9 & 51.1 & 50.5 & 45.8 \\
\hline
\end{tabular}

leads to an orderly evolution of the water resources system and a lack of cooperation leads to disorder. The degree of cooperation among order parameters can be expressed as order degree, which represents the character of order and organization.

There are mainly two principles to identify the order parameters of a water resources system: the first is the scientific principle, namely that order parameter selection should be based on synergetic theory and a water resources system's evolution mechanism, and the chosen order parameters must govern other parameters and dominate the evolution process; the second is the practical principle, in which order parameter selection should fully consider operability and data availability.

According to the above two principles and considering the reality and character of water resources in Beijing, the selected order parameters (seen in Table 1) of the water resources system of Beijing are described as follows:

1) Order parameters for resource subsystem should reflect the stability and renewable capability of a water resources system. The utilization ratio (UR) of water resources, as a common indicator, is expressed as the ratio of local total fresh water supply to the total volume of water resources. It can reflect the development and utilization level of water resources. The larger the UR, the higher the development level of water resources and the lower the water resources renewability. Hence, we chose UR as one order parameter. Groundwater supplies most of the water demand of Beijing with a proportion of more than $77 \%$ (in 2004 in particular). Groundwater level (GL) measures a regional groundwater extraction capacity to the same extent, and reflects the change in groundwater storage. In other words, GL reflects the stability and renewable capability of the water resources system that is the property of a resource subsystem. Therefore, GL is the right order parameter for Beijing.
2) Order parameters for social subsystem should reflect the safeguard capacity of adequate supplies of clean water and the equity of water use. Tap water is the best way to supply clean water for local residents. Tap water production capacity (TPC) reflects the safeguard capacity of adequate supplies of clean water for local residents. Therefore, TPC is an appropriate order parameter. In Beijing, inequality of water use occurs mainly in rural areas. Particularly the marginalized and poorer users living in rural areas have a lot of inconveniences to obtain the adequate quantity and quality of water necessary to sustain their well-being. Spatial equity of water use (SE) is the ratio of urban per capita domestic water consumption to rural per capita domestic water consumption, which is a feasible indicator describing the equity of water use. Therefore, SE was selected as one order parameter of the social subsystem.

3) Order parameters for the economic subsystem should reflect the supporting role of economic activities and the efficient use of water resources. Water is one of the basic resources in economic activities supporting economic development. Gross domestic product (GDP) per capita (GDP-PC) is the output of a region's economy per person and a measurement of a region's prosperity. In this case, GDP-PC can reflect how much of a supporting role water plays in an economy to a certain extent. Hence, GDP-PC can be used as an order parameter. Water consumption per 10,000 yuan GDP (WCP-GDP) means the ratio of total water resources consumption by variety to GDP, which can reflect the efficient use of water resources from an economic perspective. The smaller the WCP-GDP, the higher the water efficiency. Therefore, WCP-GDP is an appropriate order parameter of economic subsystems.

4) Order parameters for ecological subsystems should reflect the inherent ecological function of water 
resources under natural conditions. Ecological water requirement satisfaction may be one of the most optimal order parameters. It measures the degree of water resources meeting the water requirement of the local ecological system. However, owing to the unavailable data, ecological water requirement satisfaction was not selected for this study. Ecological water consumption (EWC) measures the water consumption of a water ecosystem within a region, i.e. the water consumption needed to maintain the biomes and habitats of the water ecosystem's dynamic stability. EWC can also reflect the reality of a water ecosystem. Therefore, we choose it as an order parameter. As mentioned above, Beijing has suffered many water problems as many rivers have dried up, and the ecosystem has suffered serious damage. Dry river rate (DRR) is defined as the ratio of dry river length to the total length of the monitored rivers, which can reflect a river's ecological conditions directly. When DDR $>0$, then some reaches of monitored rivers or one whole river had run dry, implying that a river's ecosystem had destroyed with ecological function un-maintenance and separated biological diversity. The larger the DRR, the worse the water ecosystem. In this case, since DRR is very suitable for Beijing, we selected it.

5) Order parameters for environmental subsystems should reflect the overall situation of local water quality. For this case, the total pollutant discharge or COD discharge into water may be one of the best order parameters. But there are not enough data for these two parameters. Wastewater treatment rate (WTR) is defined as the ratio of wastewater disposed to the total discharge of wastewater, which determines the total amount of pollutants into the water and reflects the degree of compensation for human-caused water environmental pollution. The higher this ratio, the less sewage discharged into the environment - or the less pollutant (which can be measured as COD) discharged into water. Hence, WTR can be used to replace the total pollutant discharge or COD discharge into water as an order parameter. River water quality index (RQI) refers to the ratio of river length reaching water quality standard to the whole evaluated river length, which can reflect surface water quality. We can easily know the changes in the river water environment in Beijing from changes in the value of RQI. Therefore, RQI is an appropriate order parameter of an environmental subsystem as well. The order degree of these order parameters can be calculated as follows:

$$
\begin{aligned}
d_{i j}\left(e_{i j}\right) & =\frac{e_{i j}-\operatorname{Min}\left(e_{i j}\right)}{\operatorname{Max}\left(e_{i j}\right)-\operatorname{Min}\left(e_{i j}\right)} \\
d_{i j}\left(e_{i j}\right) & =\frac{\operatorname{Max}\left(e_{i j}\right)-e_{i j}}{\operatorname{Max}\left(e_{i j}\right)-\operatorname{Min}\left(e_{i j}\right)}
\end{aligned}
$$

$$
d_{i j}\left(e_{i j}\right)=1-\frac{\left|e_{i j}-c\right|}{\operatorname{Max}\left(e_{i j}\right)-\operatorname{Min}\left(e_{i j}\right)}
$$

...where $d_{i j}\left(e_{i j}\right)$ is the order degree of order parameter $e_{i j}$, $e_{i j}$ is the value of the $i$ th order parameter of the $j$ th subsystem $(j=1,2, \ldots, 5), \operatorname{Max}\left(e_{i j}\right)$ and $\operatorname{Min}\left(e_{i j}\right)$ are respectively the maximum and minimum values of order parameter $e_{i j}$, and $c$ is a critical value between $\operatorname{Max}\left(e_{i j}\right)$ and $\operatorname{Min}\left(e_{i j}\right)$. (Note that order degree is a relative value between 0 and 1 , where 0 does not mean absolute disorder, and 1 does not mean absolute order.)

If an increase in the value of an order parameter will result in an increase in its order degree and a more optimum result for the corresponding system, then its order degree is calculated using equation (1). Otherwise, use equation (2). If the value of an order parameter approaching critical value $c$ will cause an increase in its order degree, then its order degree is calculated using equation (3). For the water resources system, the order parameter of GL, TPC, GDPPC, EWC, WTR, and RQI should use equation (1), while UR, WCP-GDP, and DRR adopt equation (2), and SE uses equation (3). SE can measure the fairness level of people living in urban and rural areas obtaining an adequate quantity and quality of water necessary to sustain human wellbeing. From the perspective of equity of water use, they should enjoy the same service of water supply and equal basic water use. Therefore, the critical value $c=1$.

On the basis of the order degrees of order parameters, the order degree of a subsystem can be expressed as:

$$
\mathrm{D}_{j}=\sum_{i=1}^{n} \lambda_{i} d_{i j}\left(e_{i j}\right)
$$

...where $\lambda_{i} \geq 0, \sum_{i=1}^{n} \lambda_{i}=1, D_{j}$ is the order degree of the $j$ th subsystem, and $\lambda_{i}$ is the weight of $d_{i j}\left(e_{i j}\right)$.

The relative value of order degree of the subsystem reflects the order and development status of each subsystem, and a higher value of the order degree represents more harmony and order of the subsystem. However, because of the limited water resources at a certain time, the order degrees of different subsystems cannot be a maximum at the same time. If the order degree of one subsystem increases, that of another subsystem may decrease, but the harmony state of the whole water resources system and its evolutionary process and how to quantitatively predict its evolution direction are still unknown, due to the very complicated relationship (interacted, inter-restricted, e.g. competition and cooperation) among the five subsystems.

As mentioned above, entropy can be considered an expression of the disorder, or randomness of a system, and interpreted as a measure of the degree of disorganization in a system and reflect the tendency for any state of affairs to lose order. In this case, entropy can be interpreted as a negative order degree. Therefore, this article introduced entropy 
theory in the study and created a system evolution entropy function combined with synergetic theory to demonstrate the evolutionary process of a water resources system.

\section{Entropy Theory and Water Resources System}

The concept of entropy is derived from thermodynamics, where it was used to state the second law of thermodynamics. Rudolf Clausius defined entropy (symbolized by $S$ ) of a system in terms of a path integral over its differential, namely $\mathrm{d} S=\mathrm{d} Q / T$, where $T$ is the absolute temperature and $\mathrm{d} Q$ is the differential of heat flow. He showed that $\mathrm{d} S>0$ for all irreversible thermodynamic processes; i.e., the entropy of an isolated system is non-decreasing [33].

In statistical thermodynamics, entropy was often expressed as the logarithm of the number of microstates in a macrostate of a system. Ludwig Boltzmann developed a statistical mechanical evaluation of entropy $S$, that $S=k_{B} \ln \Omega$, where $k_{B}$ denotes Boltzmann's constant and $\Omega$ denotes the number of microstates consistent with the given equilibrium macrostate [34].

Later, Shannon introduced the Boltzmann entropy in information theory and considered entropy as a measure of the uncertainty of random events or the amount of information, and developed the concept of information entropy [35]. Considering a process with $n$ possible outcomes having probabilities $p_{1}, p_{2}, \ldots, p_{n}$, the information entropy (also called Shannon entropy) is defined as:

$$
\mathrm{S}=-\sum_{i=1}^{n} p_{i} \ln p_{i}
$$

...where $\sum_{i=1}^{n} p_{i}=1$.

Whether from the perspective of statistical entropy or information entropy, entropy can be considered as a measure of the disorder in the system; the higher the entropy, the greater the disorder. In this case, the higher the order degree of a system, the smaller its entropy.

The exchange of matter, energy, and information between the open system and its surroundings can cause changes in entropy, accompanied by entropy generation due to the irreversible processes. Therefore, the variation of system entropy $d S$ is composed of two parts:

$$
\mathrm{d} S=\mathrm{d}_{i} S+\mathrm{d}_{e} S
$$

...where $\mathrm{d}_{i} S$ is the entropy generation due to irreversible processes within the system and $\mathrm{d}_{i} S \geq 0 ; \mathrm{d}_{e} S$ is the change in entropy due to exchanges between the surroundings and the system, and it can be negative or positive.

Therefore, the change of the system entropy depend on the logical relationship between these two parts. If $\mathrm{d}_{e} S$ is negative and greater than $\mathrm{d}_{i} S$, a situation may be obtained where $\mathrm{d} S<0$, i.e., where the net entropy of the system is negative. Then the system enters a relatively orderly state.
A water resources system is a complicated system giant that includes exchanges of matter, energy, and information with the surrounding environments, i.e., the existence of the entropy change. Similarly, the entropy of the water resources system is composed of $\mathrm{d}_{i} S$ and $\mathrm{d}_{e} S$ based on entropy theory due to the irreversible processes of a water resources system, $\mathrm{d}_{i} S \geq 0$. Due to the exchanges of matter, energy, and information between the water resources system and the surrounding environments, $\mathrm{d}_{e} S$ can be negative or positive. For example, over-withdraw of freshwater and over-discharge of wastewater can produce entropy, while scientific and sustainable water resources management can lose entropy. However, the reality of a water resources system presents both entropy increase caused by adverse interference of human activities, and entropy decrease caused by scientific water resources management. The overall change of the water resources system entropy is difficult to know simply. If $\mathrm{d}_{e} S$ is continuously negative and its absolute value greater than $\mathrm{d}_{i} S$ over years, then the water resources system entropy $\mathrm{d} S$ is decreasing, indicating the order degree is continuously increasing and the water resources system is evolving toward order, otherwise the water resources system is evolving disorder. Hence, we can use the change of entropy to demonstrate the evolution direction of a water resources system. Generally, we call this entropy evolution entropy.

\section{Evolution Entropy of Water Resources System}

Based on information entropy and the relationship of order degree and entropy, the evolution entropy of water resources system is expressed as:

$$
S_{E}=-\sum_{j=1}^{5} \frac{1-D_{j}}{\sum_{\mathrm{j}=1}^{5}\left(1-D_{j}\right)} \ln \frac{1-D_{j}}{\sum_{\mathrm{j}=1}^{5}\left(1-D_{j}\right)}
$$

...where $S_{E}$ is the evolution entropy of the water resources system, $D_{j}$ is the order degree of the $j$ th subsystem, and $\mathrm{D}_{1}$, $\mathrm{D}_{2}, \mathrm{D}_{3}, \mathrm{D}_{4}$, and $\mathrm{D}_{5}$ are the order degree of the resource subsystem, social subsystem, economical subsystem, ecological subsystem, and environmental subsystem, respectively.

The evolution entropy of the water resources system $\left(S_{E}\right)$ appears as a measure of the degree of order/disorder of the water resources system, so it can provide useful information about the evolution of the system, e.g. showing the evolution process and helping to predict the future evolution direction. If $S_{E}$ continues to decrease, this indicates that order degree is increasing and the water resources system is evolving toward order. Since evolution entropy is a state function, the change in entropy from a given initial state to a given final state can also be represented by $\Delta S_{E}$ :

$$
\Delta S_{E}=S_{E}(t+1)-S_{E}(t)
$$

...where $\Delta S_{E}$ is the change of $S_{E}$ from the initial state in $t$ time to the final state in $(t+1)$ time, $S_{E}(t+1)$ is the evolution 
Table 2. Order degree of subsystems and system evolution entropy in 2000-13.

\begin{tabular}{|l|c|c|c|c|c|c|c|c|c|c|c|c|c|c|}
\hline \multirow{2}{*}{\multicolumn{1}{|c}{ Item }} & \multicolumn{10}{|c|}{ Year } \\
\cline { 2 - 14 } & 2000 & 2001 & 2002 & 2003 & 2004 & 2005 & 2006 & 2007 & 2008 & 2009 & 2010 & 2011 & 2012 & 2013 \\
\hline Resource subsystem & 0.50 & 0.55 & 0.47 & 0.51 & 0.56 & 0.54 & 0.47 & 0.44 & 0.55 & 0.38 & 0.37 & 0.40 & 0.53 & 0.42 \\
\hline Social subsystem & 0.52 & 0.49 & 0.55 & 0.61 & 0.22 & 0.23 & 0.41 & 0.61 & 0.71 & 0.70 & 0.77 & 0.65 & 0.68 & 0.81 \\
\hline Economic subsystem & 0.00 & 0.13 & 0.27 & 0.33 & 0.44 & 0.52 & 0.59 & 0.68 & 0.73 & 0.76 & 0.83 & 0.90 & 0.95 & 1.00 \\
\hline Ecological subsystem & 0.40 & 0.22 & 0.12 & 0.03 & 0.08 & 0.21 & 0.20 & 0.44 & 0.73 & 0.80 & 0.63 & 0.66 & 0.87 & 0.99 \\
\hline Environmental subsystem & 0.27 & 0.34 & 0.30 & 0.62 & 0.51 & 0.46 & 0.70 & 0.49 & 0.59 & 0.46 & 0.51 & 0.60 & 0.60 & 0.50 \\
\hline System evolution entropy & 0.682 & 0.686 & 0.687 & 0.670 & 0.681 & 0.687 & 0.676 & 0.689 & 0.688 & 0.658 & 0.655 & 0.650 & 0.610 & 0.462 \\
\hline Entropy change & & 0.004 & 0.001 & -0.018 & 0.012 & 0.006 & -0.011 & 0.013 & -0.001 & -0.030 & -0.003 & -0.004 & -0.040 & -0.148 \\
\hline
\end{tabular}

entropy of $(t+1)$ time, $S_{E}(t)$ is the evolution entropy of $t$ time, and $t$ is the time period that can refer to the year, day, hour, or second and others. In this paper, $t$ represents the year.

Combining equations (6) and (8), $\Delta S_{E}$ can also be calculated as:

$$
\begin{aligned}
& \Delta S_{E}=S_{E}(t+1)-S_{E}(t) \\
& =\left(\Delta_{i} S_{E}(t+1)-\Delta_{i} S_{E}(t)\right) \\
& +\left(\Delta_{e} S_{E}(t+1)-\Delta_{e} S_{E}(t)\right)
\end{aligned}
$$

...where the first part $\left(\Delta_{i} S_{E}(t+1)-\Delta_{i} S_{E}(t)\right)$ is the evolution entropy generation due to irreversible processes within the water resources system from the $t$ time to $(t+1)$ time, and the second part $\left(\Delta_{e} S_{E}(t+1)-\Delta_{e} S_{E}(t)\right)$ is the change in evolution entropy due to exchanges between the water resources system and its surroundings during the same period. From the above theory, we know that the first part is always positive and the second part is uncertain, namely it may be negative or positive.

$\Delta S_{E}$ may be less than, equal to, or greater than zero. Then it can be used as a visual indicator to present the evolution process of water resources system over the years. If $\left(\Delta_{e} S_{E}(t+1)-\Delta_{e} S_{E}(t)\right)<0$ and $\left|\left(\Delta_{e} S_{E}(t+1)-\Delta_{e} S_{E}(t)\right)\right|>$ $\left(\Delta_{i} S_{E}(t+1)-\Delta_{i} S_{E}(t)\right)$, then $\Delta S_{E}<0$, implying the process of evolution entropy reduction and the orderly evolution of water resources system. On the contrary, if $\left(\Delta_{e} S_{E}(t+1)-\right.$ $\left.\Delta_{e} S_{E}(t)\right)<0$ and $\left|\left(\Delta_{e} S_{E}(t+1)-\Delta_{e} S_{E}(t)\right)\right|<\left(\Delta_{i} S_{E}(t+1)-\right.$ $\left.\Delta_{i} S_{E}(t)\right)$, or $\left(\Delta_{e} S_{E}(t+1)-\Delta_{e} S_{E}(t)\right)>0$, at these two conditions, $\Delta S_{E}>0$, implies the process of evolution entropy increase and the water resources system evolving toward disorder. If $\left(\Delta_{e} S_{E}(t+1)-\Delta_{e} S_{E}(t)\right)<0$ and $\left|\left(\Delta_{e} S_{E}(t+1)-\Delta_{e} S_{E}(t)\right)\right|=$ $\left(\Delta_{i} S_{E}(t+1)-\Delta_{i} S_{E}(t)\right)$, then $\Delta S_{E}=0$, indicating that the water resources system became stationary.

\section{Results and Discussion}

\section{Evolution Process of Water Resources System in $2000-13$}

The data of the order parameters (Table 1) from 2000 to 2013 were obtained from the Beijing Statistical Yearbook 2014 [36], Beijing Water Statistical Yearbook 2013 [37], and Beijing Water Resources Bulletin from 2000 to 2013 plus supplements [38]. The order degree of these order parameters was calculated using equations (1), (2), and (3); the results are shown in Table 2. Then using equation (4), we obtained the order degree of the five subsystems (see Table 2 and Fig. $1 ; \lambda_{i}$ was set equally, assuming that all parameters have the same importance in the respective sub-

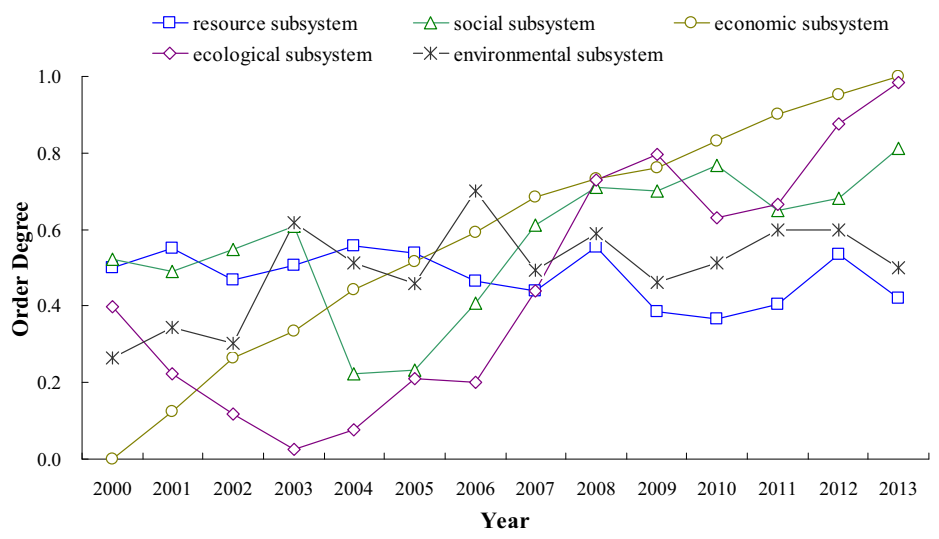

Fig. 1. Order degree of the five subsystems in 2000-13. 


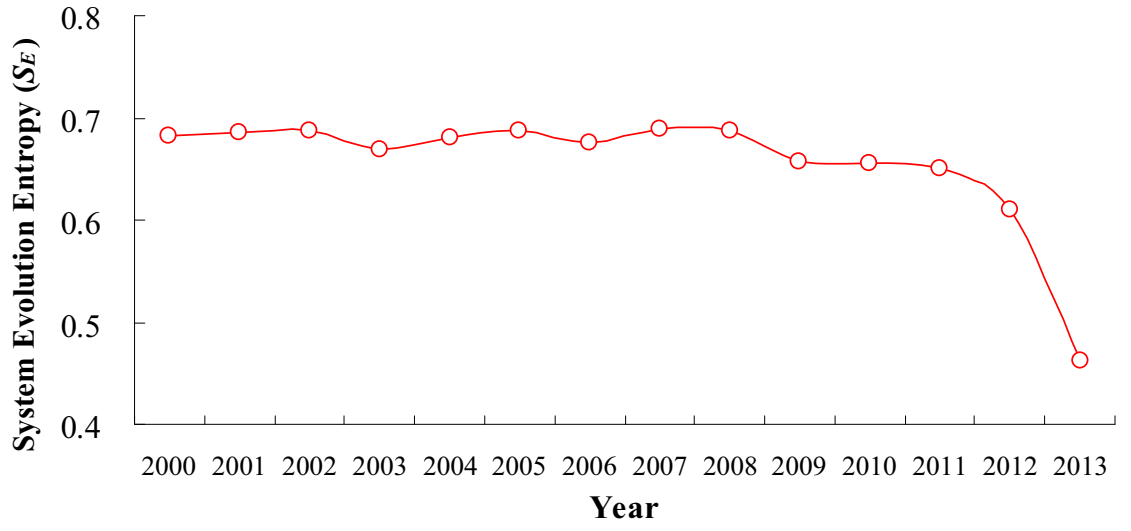

Fig. 2. Evolution entropy of the water resources system in 2000-13.

system). In terms of the above values, the evolution entropy of the Beijing water resources system was calculated according to Eq. (7) (Table 2 and Fig. 2).

From Table 2 and Fig. 1 it is obvious that the order degree of economic subsystem continues to increase, indicating that the supporting role of the water resources system of industrial production and economic development is growing, and water use efficiency is increasing. The order degree of the social subsystem is on an overall upward trend, suggesting that the safeguard level of water resources system for residential water demand increases, and the equity of water use grows within the study period. The order degree of the ecological subsystem also shows an increasing tendency from 2003 to 2013, indicating that Beijing's aquatic ecosystem shows a tendency to improve. The order degree of resource subsystem and environmental subsystem all present a fluctuated trend.

It is clear from Table 2 and Fig. 2 that the evolution entropy of a water resources system is on an overall declining trend, with a fluctuation within a narrow range from 2000 to 2007, and a dramatic decline since 2008. The evolution entropy of water resources system in 2000 is 0.682 , reaches its maximum (0.689) in 2007, and then lowers to its minimum (0.462) in 2013, especially that the evolution entropy experienced a general and sharp reduction from 2008 to 2013. The overall downward trend of evolution entropy reflects that the water resources system in Beijing gradually developed in an orderly way, i.e., the water resources system evolved toward order as a whole during the study period. The fluctuation of evolution entropy within a narrow range from 2000 to 2007 indicates that there is only a slight change of a water resources system's state, i.e., the water resources system became stationary basically for this period. The sharp reduction of evolution entropy from 2008 implies that the water resources system evolved toward order quickly.

$\Delta S_{E}$ is another visual indicator. Fig. 3 shows that $\Delta S_{E}$ fluctuated around zero from 2000 to 2007 , but after 2008, $\Delta S_{E}<0$ all the time. In other words, after 2008, according to Eq. (9), $\left(\Delta_{e} S_{E}(t+1)-\Delta_{e} S_{E}(t)\right)<0$ and $\mid\left(\Delta_{e} S_{E}(t+1)-\right.$ $\left.\Delta_{e} S_{E}(t)\right) \mid>\left(\Delta_{i} S_{E}(t+1)-\Delta_{i} S_{E}(t)\right)$. This reflects the fact that the entropy decreases from the surrounding environments owing to the scientific and sustainable water resources management and water projects (e.g. water ecological environment improvement projects, water resources protection projects) and exceeds the entropy increases from the irreversible processes of a water resources system. The water resources system of Beijing evolved toward order after 2008.

The above changes correspond strongly with the reality of Beijing. In order to safeguard the Beijing 2008 Summer Olympic Games, after winning the bid in 2001 the city began large-scale construction of municipal infrastructures and eco-environmental improvement projects. For water supply security, since 2002 four groundwater utilization projects (Zhangfang, Huairou, Pinggu, and Changping) were initiated for emergency water use. They were completely built in 2005 with an annual average water with-

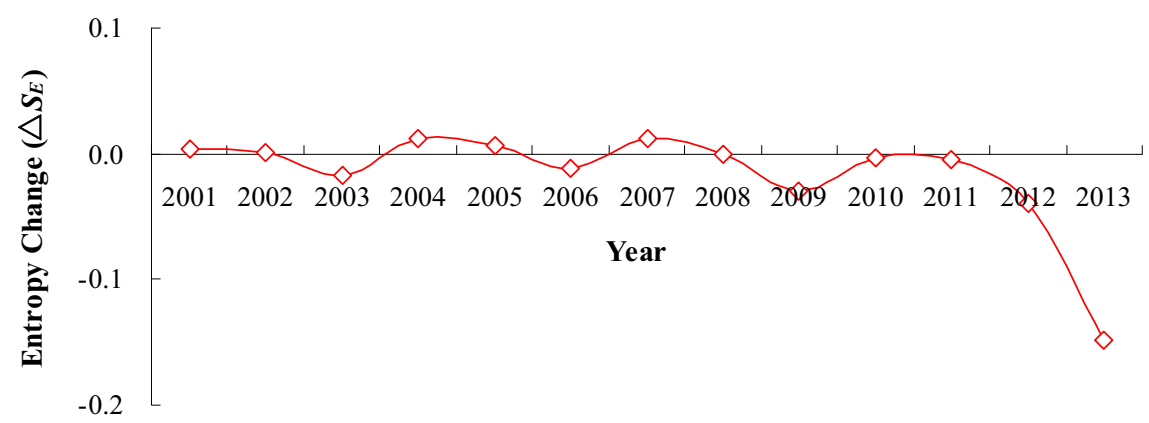

Fig. 3. Entropy change of the water resources system in 2000-13. 
drawal of 300 million $\mathrm{m}^{3}$. The Beijing-Shijiazhuang section of the middle route of the South-to-North Water Diversion Project was completed in 2008, and 70 million $\mathrm{m}^{3}$ water was transferred from Hebei province to Beijing, and the transferred water quantity increased to more than 200 million $\mathrm{m}^{3}$ per year after 2009. For water pollution reduction, Beijing has made substantial progress in the construction of wastewater treatment facilities and reclaimed water projects. For example, Qinghe and Xiaohongmen wastewater treatment plants were built in 2003 and 2005 and their capacity has reached 0.4 million and 0.6 million $\mathrm{m}^{3}$ per day, respectively. For the requirements of the public and 2008 Summer Olympic Games for the beautiful water environment, massive river control and water environmental improvement projects were implemented in succession, such as the Olympic Park River, an urban trunk river.

At the same time, Beijing also implemented a series of scientific and integrated water resource management measures, e.g. the Construction of a Water-Saving Society and the Strictest Water Resources Management System. The Construction of a Water-Saving Society is classified as Beijing's long-standing policy. In 2005 the Beijing Municipal Government issued Beijing Water Saving Management Measures, and revised and improved it in 2010. The undertaken water-saving measures mainly refer to the promotion of water-saving appliances and construction of water-saving residential buildings in terms of domestic water, and the promotion of drip irrigation and other water-saving irrigation techniques and the implementation of water-saving irrigation system in agricultural water use. For industrial water use, implementation of industrial restructuring, elimination of high water consumption industrial enterprises, and industrial water recycling are the main water-saving measures. As of 2013, the penetration rate of household water-saving appliances reached $95 \%$ in the whole city. Agricultural water use decreased from 1.65 billion $\mathrm{m}^{3}$ in 2000 to 0.91 billion $\mathrm{m}^{3}$ in 2013. Additionally, since 2000 Beijing's industrial water use declined continuously, reduced to about half by 2013. The implementation plan for the Strictest Water Resources Management System was carried out in Beijing for many years by setting out the Three Red Lines, i.e., control of development and utilization of water resources, control of water use efficiency, and restriction of pollutants in water function areas. Moreover, this implementation plan and the control targets for the Three Red Lines have been incorporated into the local government's performance appraisal. What is more, the Beijing Water Authority was established to implement integrated water resources management in 2004, ending the situation of uncoordinated management by multiple agencies.

Around 2008 these built-water infrastructures and ecoenvironmental improvement projects began to work and be fully functional. The above massive scientific and integrated water resources management measures guaranteed water infrastructures to be stable, efficient, and effective, and maintained the sustainable development of water resources. Beijing's wastewater treatment facility capacity increased from 0.59 million $\mathrm{m}^{3}$ per day in 1999 to 3.29 million $\mathrm{m}^{3}$ per day in 2008 (an increase of 4.6 times), then to 3.93 million $\mathrm{m}^{3}$ per day in 2013; the corresponding WTR rose from $25 \%$ to $78.9 \%$ and then to $84.6 \%$ in 2013 . The annual use of reclaimed water increased from 0.21 billion $\mathrm{m}^{3}$ in 2003 to 0.6 billion $\mathrm{m}^{3}$ in 2008, approaching an increase of two times, then reached 0.8 billion $\mathrm{m}^{3}$ in 2013 , accounting for 22.1 percent of the city's water supply. Owing to the massive transfer water and reclaimed water use, the average annual UR decreased from $174.4 \%$ in $2000-07$ to $96.5 \%$ in 2008-13. The average decline in GL reduced from $0.9 \mathrm{~m}$ in 2000-08 to $0.1 \mathrm{~m}$ in 2009-13.

Therefore, industrial and domestic water use were met and the water eco-environment was improved, thus guaranteeing the successful hosting of the Beijing Olympic Games. After the Olympics, Beijing's water resources system began to go away from the oscillation state during the period of 2000-07 in 2008, and evolved toward order fast with a continuously decreasing system of evolution entropy. This also demonstrates that the implemented management policies and measures of water resources are scientific and effective, and have played active roles in improving Beijing's water resources sustainability and water resources system evolving toward order.

However, Table 1 also shows that UR was very high (higher than $100 \%$ in most years) during the study period 2000-13, and GL was still reduced (reflecting that groundwater was still over-exploitated), seriously affecting the sustainable development of water resources. Meanwhile, although DRR was on an overall declining trend but still greater than zero from 2000 to 2013, implying that the river ecosystem is improving but some reaches or rivers still run dry and the water ecosystem in Beijing has not been completely restored. Additionally, almost all the RQI of the study years were below $60 \%$, indicating that the overall condition of Beijing's water environment was severe.

\section{Evolution Direction of Water Resources System within the Next Few Years}

As a large infrastructure megaproject, the middle route of the South-to-North Water Diversion Project diverts water from Danjiangkou Reservoir on the Hanjiang, a tributary of the Yangtze River, to Beijing through canals. The water supply area of this diversion project in Beijing consists of eight urban districts and nine satellite townships, serving a population of more than nine million. And 14 water plants are to be constructed to receive water from the diversion project, while some existing water plants will be renovated so that they can receive and process the transfer water [39]. According to the General Plan of Beijing South-to-North Water Diversion Project [40], the total tap water production capacity of the newly-built and expanded water plants will reach 2.6 million $\mathrm{m}^{3}$ per day, a capacity about half of that in 2013. And a length of about $107 \mathrm{~km}$ water supply loop will be built to supply water to these water plants. Along with the middle route of the South-to-North Water Diversion Project starting to supply water to Beijing, 1.05 billion $\mathrm{m}^{3}$ water per year will be supplied to Beijing mainly for domestic and industrial water use before 2020. In addition, 
transferred water is used prior to using local water so that local water can be saved and stored, and most private wells will be sealed to protect groundwater supplies [39, 40]. What is more, Beijing will recharge groundwater in the main groundwater sources (e.g. sources of the groundwater utilization projects) in order to conserve and store local groundwater, safeguarding long-term supply security. Therefore, local water resources utilization will decrease, and especially the amount of groundwater exploitation will be reduced significantly. Then UR will decrease considerably. The groundwater will be conserved, and its levels will gradually rise. The stability and renewable capability of water resource system will be enhanced, thereby the order degree of the resource subsystem will increase. Furthermore, with the implementation of the General Plan of Beijing South-to-North Water Diversion Project, TPC will undoubtedly increase, thereby a more safeguard capacity of adequate supplies of clean water for local residents. Additionally, along with the 1.05 billion $\mathrm{m}^{3}$ transferred water per year supplies to Beijing, the water shortage in Beijing will alleviate. Then users living in rural areas, especially marginalized and poorer users, will have more chance to get adequate water. In this case, spatial equity of water use will be reflected. Therefore, the order degree of the social subsystem will increase.

In order to further enhance wastewater treatment and reclaimed water capacity, the Beijing Municipal Government issued its Three-year Action Plan of Sewage Treatment and Recycled Water Facilities Construction (2013-2015) in 2013. By 2015, 47 reclaimed water plants will be built and 20 sewage treatment plants will be upgraded. Beijing's wastewater treatment facility capacity will increase by 2.28 million $\mathrm{m}^{3}$ per day - an increase of about $58 \%$ that of 2013 , and the corresponding WTR plans to rise to more than $90 \%$ in 2015 . Meanwhile, more reclaimed water will be used for replenishing river water and landscaping, etc. Therefore, pollutants into the river water will be further reduced, and the water environment will be improved significantly. Moreover, the collaborative development of Beijing, Tianjin, and Hebei province, as an innovative part of the national development strategy, will bring opportunities to achieve the regional water resources cooperation of the three regions. Beijing's integrated water resources management level will be enhanced significantly. Based on the above good situations of water resources and favorable policies, we can predict that system evolution entropy will be further reduced, and Beijing's water resources system will evolve toward order within the next few years.

\section{Conclusions}

In summary, we introduced synergetic theory and entropy theory to study the evolution of the water resources system, and explored constructing system evolution entropy to show the evolution process of the water resources system in Beijing from 2000 to 2013 under the double impacts of climate change and human intervention.
The system evolution entropies generally showed a declining trend, with a fluctuation within a narrow range from 2000 to 2007, and a dramatical decline since 2008. Although with slight oscillations in 2000-07, Beijing's water resources system evolved toward order as a whole during the whole study period, especially after 2008 . Through comparative analysis of these changes of system evolution entropy with the actual changes of the water resources system, socio-economic situations and the ecological environment in Beijing in the 14 years of 2000-13, consistency was obviously seen, i.e., the study results fit the actuality well. Therefore, this method exhibits good feasibility and adaptability, which has the following advantages:

(i) Synergetic theory and entropy theory were combined to illustrate the evolution mechanism of water resources system from the perspective of five subsystems collaboration, showing a good theoretical basis. A deep understanding of the evolution mechanism of water resources system was obtained.

(ii) The established system evolution entropy can quantitatively and easily show the evolution process of the water resources system, and also can predict the direction of evolution. These study results can provide great assistance for integrated water resources management and the sustainable development of the water resources system in Beijing.

We hope the method proposed in this paper can be adapted to the study of other cities or regions, and believe that it will become more reliable with a better understanding of the evolution mechanism, such as optimization selection of order parameters based on different water resources conditions in different regions.

We consider that optimization selection of order parameters is the key issue when this method was adapted in other cities or regions with different water resource conditions. Besides the two principles, namely scientific principle and practical principle, the optimization selection of order parameters should adequately consider the local reality, for instance climate, water supply sources, water environment, water ecology, etc. According to our study, considering the properties of the five subsystems, for resource subsystem, UR should be selected because it may be the best parameter reflecting the development and utilization level of local water resources. Groundwater supplies most of the water demand in Beijing. GL measures a regional groundwater extraction capacity to the same extent, and reflects the stability and renewable capability of the water resources system. Therefore, we choose GL as one order parameter of the resource subsystem. However, if in other regions, unlike Beijing, surface water is the main supply source, the order parameter can select parameters that reflect surface water supply capacity, e.g. the total reservoir storage capacity for water supply. Order parameters of the social subsystem and economic subsystem are applicable to different water resource conditions, which thereby can be retained. As for ecological subsystems, ecological water requirement satisfaction is superior to EWC. For regions without rivers drying up, order parameter can select the biodiversity index of water ecology or others. For coastal 
areas, the quantity of water discharge into the sea or estuarine ecological flow may be excellent order parameters. As for environmental subsystems, total pollutant discharge or COD discharge into water may be one of the best order parameters. However, WTR and RQI are also suitable order parameters due to the practical principle. After all of the order parameters are selected, one can calculate the order degree using equations (1), (2), (3), and (4), and then obtain evolution entropy using equation (7). Afterward, the evolution process of the water resource system was shown through the changes of entropy. Consequently, the method proposed in this paper can be better used in other regions even with different water resource conditions.

\section{Acknowledgements}

We gratefully acknowledge financial support from the Planning Research for Ecological Restoration and Water Resources Protection in the Yongding River Basin (Grant No. D09040900400000), the Study and Application on Groundwater Resources Safety and Pollution Control and Prevention Technology in Beijing (Grant No. D07050601510000), and the Special Research Foundation for the Public Welfare Industry of the Ministry of Water Resources of China (Grant No. 201301005).

\section{References}

1. PANDEY V. P., BABEL M. S., SHRESTHA S., KAZAMA F. A Framework to Assess Adaptive Capacity of the Water Resources System in Nepalese River Basins. Ecol. Indic. 11, (2), 480, 2011.

2. ASEFA T., CLAYTON J., ADAMS A., ANDERSON D. Performance Evaluation of A Water Resources System Under Varying Climatic Conditions: Reliability, Resilience, Vulnerability and beyond. J. Hydrol. 508, 53, 2014.

3. LI Y., LENCE B. J. Estimating Resilience for Water Resources Systems. Water Resour. Res. 43, W07422, 2007. doi: 10.1029/2006WR005636

4. LIU D. D., CHEN X. H., NAKATO T. Resilience Assessment of Water Resources System. Water Resour. Manag. 26, 3743, 2012.

5. DU C. Y., YU J. J., ZHONG H. P., WANG D. D. Operating Mechanism and Set Pair Analysis Model of a Sustainable Water Resources System. Front. Environ. Sci. Eng. 9, (2), 288, 2015.

6. WANG W. S., JIN J. L., DING J., LI Y. Q. A New Approach to Water Resources System Assessment-Set Pair Analysis Method. Sci. China Ser. E. 52, (10), 3017, 2009.

7. AHMAD S., SIMONOVIC S. P. Spatial System Dynamics: New Approach for Simulation of Water Resources Systems. J. Comput. Civil Eng. 18, (4), 331, 2004.

8. HUI X. Y., WANG D. X., LONG A. H., NI H. Z. Constructing Coordination Evaluation Index System for Complex Water Resources System and the Corresponding Regulation Measures. J. of China Inst. of Water Resour. Hydropower Res. 9, (3), 188, 2011.

9. XU W., DU S. H. Information Entropy Evolution for Groundwater Flow System: A Case Study of Artificial Recharge in Shijiazhuang City, China. Entropy 16, (8), 4408, 2014.
10. SIENIUTYCZ S. Entropy-based Modeling and Simulation of Evolution in Biological Systems. In Computer Aided Systems Theory-EUROCAST 2007; ALBRECHT R. F., DÍAZ R. M., PICHLER F., ARENCIBIA A. Q.; Springer:Berlin Heidelberg, Germany, pp. 34-41, 2007.

11. CHAKRABARTI C. G., GHOSH K. Maximum-entropy Principle: Ecological Organization and Evolution. J. Biol. Phys. 36, 175, 2010.

12. LIN Z. M., XIA B. Sustainability Analysis of the Urban Ecosystem in Guangzhou City Based on Information Entropy between 2004 and 2010. J. Geogr. Sci., 23, (3), 417, 2013.

13. MA H. H., WANG Q., KE Q., LI G. M., XU J. C. Analysis on Evolution of Urban Ecosystem and Ability of Sustainable Development in Wenzhou. Ecol. Econ. (10), 131, 2008 [In Chinese].

14. XU J. H., GAO Y. J. The self-organizing Way, Influencing Factors and Entropy Change of Geographical System Evolution. J. Syst. Dialectic. 9, (3), 53, 2001.

15. LIU Y., HU A. Y., DENG Y. Z. Study on the Evolution of Water Resource Structure Based on Information Entropy. J. Northwest Sci-Tech Univ. Agric. and For. (Nat. Sci. Ed.). 34, 141, 2006 [In Chinese].

16. MA L. H., KANG S. Z., SU X. L. Study on Evolution and Its Driving Forces of Water Utilization Structure of Shiyang River Basin in Northwest Arid Areas. Agric. Res. in the Arid Areas. 26, (1), 125, 2008.

17. WANG X. J., ZHANG J. Y., HE R. M., WANG Y. C. Study on the Evolution Law of Water Utilization Structure and Regulating Approach in Yulin City. China Popul. Resour. Environ. 21, (2), 61, 2011.

18. JIANG J. Y., ZHANG Y. D., GU H. B. Study on the Evaluation Model of Groundwater Environment Evolution Pattern Based on Grey Correlation Entropy. J. Jilin Univ. (Earth Sci. Ed.) (6), 1111, 2009.

19. FEI Y. H., MIAO J. X., ZHANG Z. J. Analysis on Evolution of Groundwater Depression Cones and Its Leading Factors in North China Plain. Resour. Sci. 31, (3), 394, 2009.

20. JU X. X., SONG C. S. River Water Quality Evolution Based on Dissipative Structure Theory and Information Entropy. Heilongjiang Sci. Technol. of Water Conservancy 34, (1), 1, 2006.

21. LIU B. J., CHEN X. H., WANG Z. L. Research on River Water Quality Evolution Based on the Dissipative Structure Theory. J. China Hydrol. 27, (1), 8, 2007.

22. ZHANG G. H., LAI Q. B., FEI Y. H., NIE Z. L. Application of the Comentropy Theory in the Evolution of Hydrologic Cycle. Site Invest. Sci. Technol. (1), 26, 2000.

23. XU X. K., CLEIDON A., WANG L. Q., DONG G. C., ZHOU X. Application of Thermodynamic Entropy in Hydrologic Cycle on Land Surface. J. China Hydrol. 30, (2), $1,2010$.

24. MU P., AI P., FANG Y. S. Review of Entropy Theory for Applications of Hydrological Cycle. Water Resour. Power 29, (10), 5, 2011

25. SU X. S., DU S. H. Information entropy evolution of groundwater flow system affected by human activity. Water Resource and Environmental Protection (ISWREP), 2011 International Symposium on IEEE. 3216, 2011.

26. ZHANG R.Q., LIANG X., JIN M.G. The evolution of groundwater flow systems in the Quaternary of Hebei Plain since the Last Glacial Maximum. Earth Sci. Front 20, (3), 217, 2013.

27. BENSE V. F., FERGUSON G., KOOI H. Evolution of shallow groundwater flow systems in areas of degrading permafrost. Geophys. Res. Lett. 36, (22), 297, 2009. 
28. BELITZ K R, HEIMES F J. Character and evolution of the ground-water flow system in the central part of the western San Joaquin Valley, California. Water Supply Papers - US Geological Survey, 1990.

29. JIANG J. Y., CAO J. F., SHENG L. I. Analysis on the Evolution of Groundwater System Using the Theory of Dissipative Structure. Res. Soil Water Conserv. 15, (1), 122, 2008.

30. LIU D, FU Q, HU Y. X., WU Q. C. Complexity measure of regional groundwater resources system based on wavelet entropy: a case study of Jiansanjiang Administration of Heilongjiang land reclamation in China. Environ. Earth Sci. 73, (3), 1033, 2015.

31. SINGH V. P. The Use of Entropy in Hydrology and Water Resources. Hydrol. Process. (11), 587, 1997.

32. SINGH V. P. The Entropy Theory As A Tool for Modeling and Decision Making in Environmental and Water Resources. Water SA. 26, (1), 11, 2000.

33. AYRES R. U. Information, Entropy, and Progress. AIP Press: New York, USA, pp. 3-5, 1994.
34. JAYNES E.T. Gibbs vs Boltzmann Entropies. Am. J. Phys. (33), 391, 1965.

35. SHANNON C. E., WEAVER W. The mathematical theory of communication. University of Illinois Press: Urbana, USA, 1949.

36. BEIJING MUNICIPAL BUREAU OF STATISTICAL. Yearbook of Statistic of Beijing 2014. China Statistics Press: Beijing, China, 2014.

37. BEIJING WATER AUTHORITY. Beijing Water Statistical Yearbook 2013. Beijing, China, 2013

38. BEIJING WATER AUTHORITY. Beijing Water Resources Bulletin (2000-2013). Beijing, China, 2000-2013.

39. DUAN W. Beijing water resources and the south to north water diversion project. Can. J. Civil Eng. 32, (1), 159, 2005.

40. BEIJING SOUTH-TO-NORTH WATER DIVERSION PROJECT CONSTRUCTION COMMITTEE OFFICE. General Plan of Beijing South-to-North Water Diversion Project. China Water Power Press: Beijing, China, 2008. 